\title{
Pengukuran Kinerja Perusahaan Menggunakan Metode Performance Prism (Studi Kasus di Cendana Offset Fokus Intermedia Grup)
}

\author{
Anissa Rianda Putri ${ }^{* 1)}$, Azmi Mas'ud ${ }^{2)}$, Selvia Mayangsari ${ }^{3)}$, dan Yuniaristanto ${ }^{4)}$ \\ ${ }^{1,2,3)}$ Mahasiswa Program Studi Teknik Industri, Fakultas Teknik, Universitas Sebelas Maret \\ ${ }^{4)}$ Dosen Program Studi Teknik Industri, Fakultas Teknik, Universitas Sebelas Maret \\ Jl. Ir. Sutami 36A Surakarta 57126
}

\begin{abstract}
This article explain about a performance measurement research in a graphic arts industry using Performance Prism method. The previous performance measurement system in that company has not been able to represent the performance of the organization. The performance prism method is used because this method complete the exiting methods. The stakeholder in CV. Cendana Offset consists of customers, investors or owners, communities, governments, employees, and suppliers. The company's system contains 10 KPI performance with 2 KPI of customers, 2 KPI of employees, 2 KPI of investor/owner, $2 \mathrm{KPI}$ of suppliers, and $2 \mathrm{KPI}$ of government. Based on the result, there is the fundamental problems in special services for customers. Based on the problem that have been discovered, this article propose several option for improvement. One of them is by providing great discounts on certain periods and improving the print quality through increasing the company resources (i.e. operator's skill and production machines).
\end{abstract}

Keywords: graphic art industry, performance measurement, performance prism

\section{Pendahuluan}

Industri grafika merupakan bidang industri yang merancang, mengembangkan, membuat, dan memperkenalkan produk yang mengandung atau berhubungan dengan kalimat dan atau gambar untuk mewujudkan informasi, ide, dan perasaan (Salim,2013). Produk yang dihasilkan dapat digunakan untuk kepentingan pembelajaran, hiburan, media publikasi, komersialisasi, dan lain sebagainya.

Indonesia menjadi salah satu negara di Asia yang memiliki pertumbuhan industri grafika yang sangat baik. Hal tersebut melahirkan banyak pengembangan produk inovatif, ide-ide bisnis yang kreatif serta menjanjikan perspektif masa depan industri percetakan yang lebih menarik. Sebagai salah satu perusahaan yang bergerak dalam bidang industri grafika, Cendana Offset yang berbadan usaha $\mathrm{CV}$ adalah sebuah bisnis yang bergerak di bidang layanan produksi grafik pertama dan satu satunya di kota Solo yang telah terintegrasi. Cendana Offset mampu melakukan proses produksi mulai dari prepress, press hingga postpress serta digital dan self publishing.

Kemampuan dalam mempertahankan kelangsungan hidup perusahaan di persaingan dunia industri grafika, sangat bergantung pada kinerja perusahaan. Selain itu, keberadaan usaha bisnis tergantung pada kemampuannya mengukur kinerja serta mengidentifikasi strategi dalam upaya meningkatkan kualitas perencanaan dan pengendalian (Ismail, 2007). Beberapa alasan utama mengapa perusahaan perlu melakukan pengukuran kinerja, antara lain karena pengukuran kinerja meruapakan alat untuk evaluasi, pengendalian, penganggaran, motivasi, pembelajaran, serta alat perbaikan perusahaan (Behn, 2003). Pengukuran kinerja dapat membantu perusahaan untuk mengkuantifikasikan tingkat efektivitas dan efisiensi yang telah dicapai perusahaan pada periode tertentu. Berdasarkan pengukuran kinerja yang telah dilakukan, perusahaan dapat segera

\footnotetext{
*Correspondance : anissariandaputri@gmail.com
} 
melakukan identifikasi masalah dan membuat perbaikan apabila hasil pengukuran kinerja perusahaan rendah.

Berdasarkan wawancara dengan ketua bagian HRD (Human Resource and Development), Cendana Offset belum memiliki suatu metode yang digunakan untuk mengukur kinerja perusahaan. Penilaian kinerja pada Cendana Offset hanya didasarkan pada tercapai atau tidaknya target tiap periode yang telah ditetapkan investor/pemilik perusahaan. Ketika perusahaan dapat memenuhi target yang ditetapkan, maka perusahaan dikatakan telah memiliki kinerja yang baik, sedangkan apabila perusahaan tidak dapat memenuhi target yang ditetapkan, maka perusahaan memiliki kinerja yang buruk. Target yang ditetapkan investor ialah mampu melakukan peningkatan profit atau keuntungan sebesar 2,5\% dari tahun ke tahun. Target perusahaan ini hanya berfokus pada keuangan saja. Kondisi ini menunjukkan bahwa Cendana Offset melakukan pengukuran kinerja hanya dari aspek finansial saja.

Pada dasarnya dalam mengukur kinerja suatu perusahaan, selain dari aspek finansial, aspek non finansial yang bersifat kuantitatif maupun kualitatif juga memberikan pengaruh yang besar pada kinerja perusahaan.Saat ini, terdapat tiga model sistem pengukuran kinerja terintegrasi yang digunakan secara luas di dunia industri yaitu: Balanced Scorecard dari Harvard Business School, Integrated Performance Measurement System (IPMS) dari Centre for Strategic Manufacturing University of Strathclyde, dan Performance Prism dari kolaborasi antara Accenture dengan Cranfield School of Management.

Vanany dan Tanukhidah (2004) dalam penelitiannya melakukan pengukuran kinerja pada sebuah perusahaan dalam bisnis hotel dengan metode Performance Prism dan metode scoring OMAX. Pada penelitian tersebut perusahaan belum merepresentasikan kinerja organisasi secara komprehensif dan integratif, sehingga menggunakan metode pengukuran kinerja Performance Prismyang dapat mengintegrasikan semua elemen perusahaan. Sulianto dan Intan (2007) melakukan pengukuran kinerja dengan metode Performance Prism di plaza hotel semarang. Berdasar hasil penelitiannya terdapat empat elemen KPI yang perlu diperbaiki serta diusulkan untuk dilakukan pengukuran kinerja di hotel tersebut secara periodik (3 bulan sekali, atau 6 bulan sekali). Arianto dan Partiwi (2009) melakukan pengukuran kinerja di PT. Petrokimia Gresik dengan menggunakan metode Performance Prism. Pada penelitiannya tersebut diusulkan perbaikan dalam penerapan konsep Supply Chain Management (SCM), Customer Relationship Management (CRM), Coorporate Social Responsibility (CSR), dan perubahan budaya kerja perusahaan. Mardiono, dkk (2011) melakukan pengukuran kinerja pada perusahaan makanan menggunakan metode pengukuran kinerja Performance Prism. Metode ini dipilih karena aspek yang diukur berdasarkan sisi stakeholder (owner, supplier, employee, customer dan government), karena para stakeholder ikut mempengaruhi keadaan perusahaan. Widyawati, dkk (2013) melakukan pengukuran kinerja pada suatu perusahaan menggunakan metode pengukuran kinerja Performance Prism. Metode ini dipilih karena ada keinginan dari pihak manajemen perusahaan, agar sistem pengukuran kinerja memperhatikan aspek kepuasan stakeholder secara komprehensif, yakni menyertakan kepentingan semua stakeholder yang terkait serta kepentingan perusahaan yang bersangkutan. Adianto, dkk (2014) melakukan penelitian pengukuran kinerja dengan menggunakan metode Performance Prism dan OMAX. Penentuan lima aspek perspeksif dengan menggunakan metode Performance Prism agar dapat dijadikan KPI yang kemudian dilakukan scoring dengan metode OMAX dan dianalisia dengan metode Traffic Light System.

Berdasarkan penelitian-penelitian yang telah dilakukan sebelumnya, maka pada penilitian ini digunakan metode pengukuran kinerja Performance Prism.Metode Performance Prism digunakan karena metode pengukuran kinerja ini menyempurnakan dua metode pengukuran kinerja lainnya, yaitu metode Balanced Scorecard danIPMS. Selain itu latar belakang digunakannya metode pengukuran dengan Performance Prism ini karena metode ini mengukur semua aspek yang berhubungan dengan stakeholder investor/pemilik, pelanggan, pekerja, supplier, pemerintah, dan masyarakat yang meliputi kepuasan maupun kontribusi dari para stakeholder tersebut yang tentunya sangat berpengaruh bagi perusahaan.

Penelitian ini telah menetapkan rumusan masalah yang akan dikaji, yaitu bagaimana hasil kinerja Cendana Offset yang diukur dengan metode pengukuran kinerja Performance Prism. 
Dari penelitian ini didapatkan suatu rekomendasi perbaikan bagi perusahaan yang digunakan sebagai obyek penelitian maupun pelaku usaha sejenis yang dapat bermanfaat bagi perusahaan tersebut dan diharapkan dapat menjamin kelangsungan perusahaan dalam jangka panjang.

\section{Tinjauan Pustaka}

Filosofi performance prism yang dipaparkan pada Gambar 1, menjelaskan bahwa performance prismberasal dari sebuah bangun prisma yang memiliki lima segi yaitu untuk atas dan bawah adalah kepuasanstakeholder dan kontribusi stakeholder. Sedangkan untuk ketiga sisi berikutnya adalah strategi, proses, dan kapabilitas.

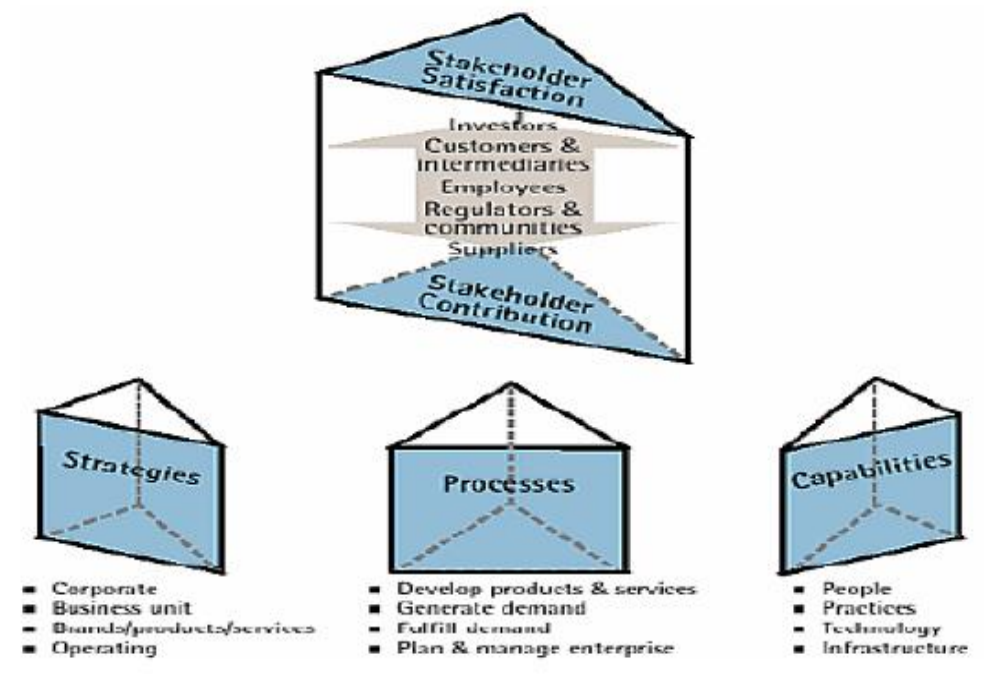

Gambar 1 Ruang Lingkup Performance Prism

Ruang lingkup performance prism merupakan interaksi antara kepuasan stakeholder dan kontribusi stakeholder yang kemudian direfleksikan dalam strategi, proses, dan kapabilitas. Terdapat enam kunci pada hubungan stakeholder

a. Investor (Shareholder)

Suatu perusahaan umum harus menerapkan usaha terbaiknya untuk membawa pada harapan para investornya.

b. Pelanggan (Customer) Perusahaan selalu ingin mempertahankan pelanggan dan menemukan lebih banyak lagi pelanggan potensial.

c. Karyawan (Employees) Perusahaan harus mempertahankan karyawan, karena hal ini berarti suatu nilai tambah bagi investor dan pelanggan (menunjukkan performance perusahaan baik), tetapi penghematan biaya harus tetap dialakukan.

d. Penyalur (Supplier) Banyaknya supplier yang memenuhi kebutuhan perusahaan akan cenderung dapat mengakibatkan pembengkakan biaya, karena mempunyai efek pada biaya administratif (misal untuk membayar faktur/invoices dll). Pengurangan biaya untuk hal ini perlu untuk secara hati-hati ditargetkan, beberapa kontrak persediaan perlu untuk dirundingkan kembali dengan para supplier. Sistem Pengukuran Kinerja Supplier difokuskan dalam rangka memonitor prestasi dan kemajuan pada penghematan biaya, hal ini tentunya perlu data-data yang akurat untuk melakukan pengukuran.

e. Pemerintah dan Masyarakat Peraturan Pemerintah secara langsung memberikan pengaruh yang besar bagi perusahaan, pemenuhan dengan peraturan merupakan suatu comformity (bukan hanya issu)

Dari penelitian ini didapatkan suatu rekomendasi perbaikan bagi perusahaan obyek penelitian maupun pelaku usaha sejenis yang dapat bermanfaat bagi perusahaan tersebut dan diharapkan dapat menjamin kelangsungan perusahaan dalam jangka panjang. 


\section{Metodologi Penelitian}

Metode penelitian yang digunakan adalah penelitian deskriptif dengan jenis penelitian metode kasus. Observasi, wawancara dilakukan pada sejumlah manajer yang dinilai berkompeten. Berdasarkan data yang ada, pengukuran kinerja dilakukan dengan menggunkan metode Performance Prism.

Awal dari konsep penelitian ini disebabkan kondisi awal perusahaan yang belum memiliki sistem pengukuran kinerja perusahaan. Sistem yang ada hanya dengan pencapaian target profit perusahaan dengan peningkatan profit per tahunnya sebesar 2,5\% dari tahun sebelumnya, sistem yang ada tersebut belum dapat merefleksikan kinerja perusahaan sehingga kurang bisa menjamin keberlangsungan perusahaan dalam jangka panjang.

Berdasarkan pemikiran awal tersebut dan penggunaan metode pengukuran kinerja Performance Prism, maka pengukuran kinerja dimulai dengan mengidentifikasikan setiap stakeholder yang terlibat dengan perusahaan. Secara umum stakeholder dari Cendana Offset terdiri dari pemilik sebagai investor, pekerja, pelanggan, supplier, pemerintah, masyarakat sekitar.

Mengidentifikasikan kepuasan (satisfaction) dari setiap stakeholder dilakukan dengan cara menyebarkan kuesioner kepada sejumlah sampel dari setiap stakeholder. Penentuan sampel kuesioner berdasarkan metode Slovin dengan jumlah populasi sebesar 100 orang dan tingkat error sebesar $10 \%$ sehingga diperoleh sampel sebesar 50 orang.Kuesioner yang digunakan ialah kuesioner jenis likert dengan lima skala penilaian dimulai dari Sangat Puas (SP) hingga Tidak Puas (TP). Identifikasi kontribusi (contribution) setiap stakeholder dilakukan dengan cara wawancara. Berdasarkan kepuasan dan kontribusi yang telah terdefinisi, maka langkah selanjutnya ialah menentukan tujuan (objective) dari masing-masing stakeholder.

Langkah pengukuran kinerja selanjutnya ialah mengidentifikasikan strategi, proses, dan kapabilitas dari masing-masing stakeholder dengan cara melakukan wawancara secara langsung. Berdasarkan tujuan, strategi, proses, dan kapabilitas yang telah terdefinisi, kemudian menentukan Performance Indicator (PI). Penentuan PI ini dilakukan dengan cara diskusi atau wawancara dengan pihak perusahaan. Setelah diperoleh PI, maka PI tersebut dibobotkan dengan menggunakan metode AHP (Analytical Hierarchy Process). Berdasarkan pembobotan dengan menggunakan AHP maka diperoleh Key Performance Indicator perusahaan.

\section{Hasil dan Pembahasan}

Berdasarkan penelitian yang telah dilakukan, berupa wawancara langsung dan penyebaran kuesioner penulis berhasil mengklasifikasikan stakeholder yang terlibat di dalam bisnis di CV. Cendana Offset. Adapun stakeholder yang terlibat terdiri dari customer, employee, investor, supplier, regulator dan communities. Setelah melakukan identifikasi stakeholder, selanjutnya adalah pendefinisian masing-masing tujuan yang dimiliki oleh stakeholder, penentuan tujuan didasarkan dari hasil wawancara dan pemberian kuesioner kepada para stakeholder. Dari hasil tersebut didapatkan 7 tujuan utama yang terdiri dari 2 tujuan customer, 1 tujuan employee, 1 tujuan investor, 1 tujuan supplier, 1 tujuan regulator dan1 tujuan dari communities.

Langkah selanjutnya setelah memperoleh tujuan dari masing-masing stakeholder yaitu mengidentifikasikan Performance Indicator (PI) berdasarkan strategi, proses dan kapabilitas dari tujuan yang dimiliki oleh stakeholder. Berdasarkan hasil identifikasi diperoleh 15 PI yang nantinya digunakan untuk proses pembobotan. Selanjutnya dilakukan penentuan hierarki untuk mendefinisikan alur sebuah PI dapat terbentuk dan menentukan bobot global yang dibutuhkan untuk mencari titik permasalahan terbesar yang perlu perhatian segera.Tabel 1 merupakan tabel yang menjelaskan tentang tujuan (objectives) serta PI dari masing-masing stakeholder. Selain itu dalam Tabel 1 juga menjelaskan tentang kode tujuan (objectives) serta PI dari masingmasing stakeholder.

Gambar 3 merupakan struktur hierarki pengukuran kinerja CV. Cendana Offset yang disusun berdasarkan identifikasi tujuan (objectives) serta PI dari masing-masing stakeholder, dan menggunakan kode yang telah ditentukan. 
Tabel 1 Identifikasi Tujuan (Objectives) dan Performance Indicator dari Stakeholder

\begin{tabular}{|c|c|c|c|c|}
\hline Stakeholder & Kode & Objective & Kode & Performance Indicator (PI) \\
\hline \multirow{4}{*}{ Customer [O] } & \multirow[b]{2}{*}{01} & \multirow[b]{2}{*}{ Peningkatan minat penggunaan jasa } & 01.1 & Rasio diskon yang diberikan \\
\hline & & & 01.2 & $\begin{array}{l}\text { Pelayanan khusus (garansi kualitas untuk order seharga > Rp } 1 \\
\text { juta) }\end{array}$ \\
\hline & \multirow{2}{*}{$\mathrm{O} 2$} & \multirow{2}{*}{ Peningkatan kecepatan dan kemudahan pelayanan } & 02.1 & Kecepatan pelayanan kepada customer \\
\hline & & & 02.2 & Kemudahan dalam pelayanan jarak jauh \\
\hline \multirow{3}{*}{ Employee $[E]$} & \multirow{3}{*}{ E1 } & \multirow{3}{*}{ Penyediaan fasilitas yang mendukung kinerja } & E1.1 & Fasilitas kerja yang memadai \\
\hline & & & E1.2 & Peningkatan kesejahteraan pekerja \\
\hline & & & E1.3 & Peningkatan kinerja pekerja \\
\hline \multirow{2}{*}{ Investor [I] } & \multirow{2}{*}{11} & \multirow{2}{*}{ Peningkatan profit/laba } & 11.1 & Peningkatan profit \\
\hline & & & 11.2 & Peningkatan kapasitas produksi \\
\hline \multirow[b]{2}{*}{ Supplier [S] } & \multirow[b]{2}{*}{ S1 } & \multirow[b]{2}{*}{ Menjalin kerja sama \& kepercayaan } & S1.1 & Menjaga kepercayaan dengan supplier \\
\hline & & & S1.2 & Keberlangsungan kerja sama antara perusahaan dengan supplier \\
\hline \multirow{2}{*}{ Regulator $[R]$} & \multirow{2}{*}{ R1 } & \multirow{2}{*}{ Menciptakan keamanan lingkungan } & R1.1 & Pemberdayaan masyarakat sekitar \\
\hline & & & R1.2 & Menciptakan keamanan dan ketertiban dilingkungan sekitar \\
\hline \multirow{2}{*}{ Communities [C] } & \multirow{2}{*}{$\mathrm{C} 1$} & \multirow{2}{*}{ Pemberdayaan sumber daya di sekitar } & C1.1 & Memberdayakan SDM sekitar perusahaan \\
\hline & & & $\mathrm{C} 1.2$ & Frekuensi keikutsertaan dalam kegiatan pemerintah \\
\hline
\end{tabular}

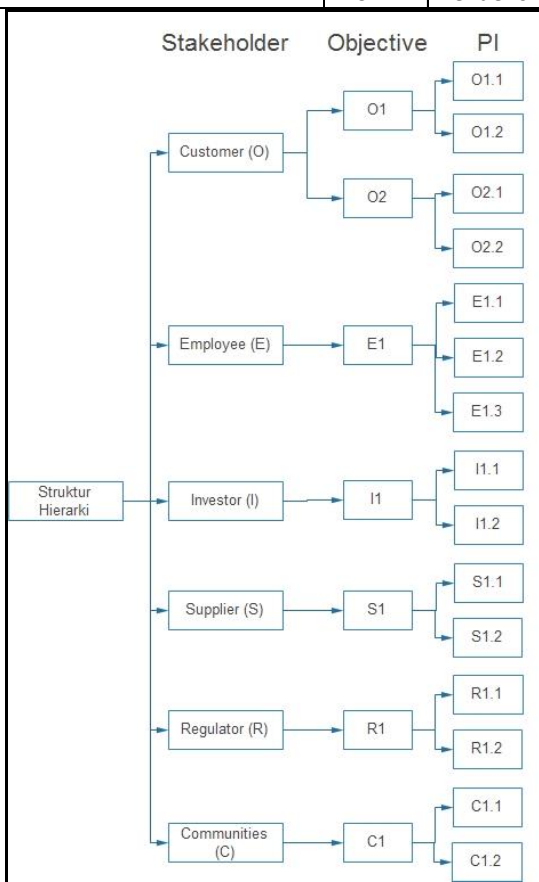

Gambar 3.Struktur Hierarki Pengukuran Kinerja

Berdasarkan hierarki pada Gambar 3, dapat dilakukan pembobotan dengan menggunakan salah satu software yang disebut Expert Choice. Pembobotan awal dilakukan pada bagian stakeholder berdasarkan kuesioner yang telah diberikan kepada pemilik, didapatkan perbandingan kepentingan dari masing-masing stakeholder yang ada, yang nantinya masingmasing perbandingan setiap stakeholder diinputkan ke dalam software untuk mendapatkan hasil pembobotan pada perbandingan stakeholder. Hasil pembobotan stakeholder dapat dilihat pada Tabel 2.

Tabel 2.Hasil Pembobotan Setiap Stakeholder

\begin{tabular}{|c|c|}
\hline Stakeholder & Bobot \\
\hline Customer [O] & 0.471 \\
\hline Employee [E] & 0.083 \\
\hline Investor [I] & 0.213 \\
\hline Supplier [S] & 0.07 \\
\hline Regulator [R] & 0.129 \\
\hline Communities [C] & 0.034 \\
\hline
\end{tabular}


Setelah melakukan pembobotan pada stakeholder dilakukan pembobotan pada masingmasing tujuan yang dimiliki atau telah ditentukan oleh stakeholder. Pembobotan dilakukan juga dengan menggunakan software Expert Choice. Hasil pembobotan dari masing-masing tujuan terdapat pada Tabel 3 .

Tabel 3.Hasil Pembobotan Setiap Tujuan dari Stakeholder

\begin{tabular}{|c|l|c|}
\hline Kode & \multicolumn{1}{|c|}{ Objective } & Bobot \\
\hline O1 & Peningkatan minat penggunaan jasa & 0.875 \\
\hline E1 & Peningkatan kecepatan dan kemudahan pelayanan & 0.125 \\
\hline I1 & Penyediaan fasilitas yang mendukung kinerja & 1 \\
\hline S1 & Menjalin kerja sama \& kepercayaan & 1 \\
\hline R1 & Menciptakan keamanan lingkungan & 1 \\
\hline C1 & Pemberdayaan sumber daya di sekitar & 1 \\
\hline
\end{tabular}

Setelah pembobotan tujuan, selanjutnya adalah pembobotan PI yang nantinya hasil pembobotan PI dan seluruh hasil pembobotan digunakan untuk menentukan masalah terbesar dan paling berpengaruh dalam kinerja perusahaan. Pembobotan PI juga dilakukan dengan menggunakan softwareExpert Choice. Hasil pembobotan dapat dilihat pada Tabel 4.

Tabel 4.Hasil Pembobotan Performance Indicator

\begin{tabular}{|c|l|c|}
\hline Kode & \multicolumn{1}{|c|}{ Performance Indicator (PI) } & Bobot \\
\hline O1.1 & Rasio diskon yang diberikan & 0.2 \\
\hline O1.2 & $\begin{array}{l}\text { Pelayanan khusus (garansi kualitas untuk order seharga > Rp 1 } \\
\text { juta) }\end{array}$ & 0.8 \\
\hline O2.1 & Kecepatan pelayanan kepada customer & 0.279 \\
\hline O2.2 & Kemudahan dalam pelayanan jarak jauh & 0.072 \\
\hline E1.1 & Fasilitas kerja yang memadai & 0.195 \\
\hline E1.2 & Peningkatan kesejahteraan pekerja & 0.717 \\
\hline E1.3 & Peningkatan kinerja pekerja & 0.088 \\
\hline I1.1 & Peningkatan profit & 0.8 \\
\hline I1.2 & Peningkatan kapasitas produksi & 0.2 \\
\hline S1.1 & Menjaga kepercayaan dengan supplier & 0.167 \\
\hline S1.2 & Keberlangsungan kerja sama antara perusahaan dengan supplier & 0.833 \\
\hline R1.1 & Pemberdayaan masyarakat sekitar & 0.088 \\
\hline R1.2 & Menciptakan keamanan dan ketertiban dilingkungan sekitar & 0.416 \\
\hline C1.1 & Memberdayakan SDM sekitar perusahaan & 0.044 \\
\hline C1.2 & Frekuensi keikutsertaan dalam kegiatan pemerintah & 0.065 \\
\hline
\end{tabular}

Selanjutnya setelah dilakukan pembobotan dari stakeholder,objective dan PI dapat dilakukan pembobotan global dengan mengkalikan bobot PI, bobot objective dan bobot stakeholder berdasarkan alur hierarki yang telah ada, sehingga didapatkan besarnya bobot global yang dapat dilihat pada Tabel 4.

Tabel 5. Pembobotan Performance Indicator

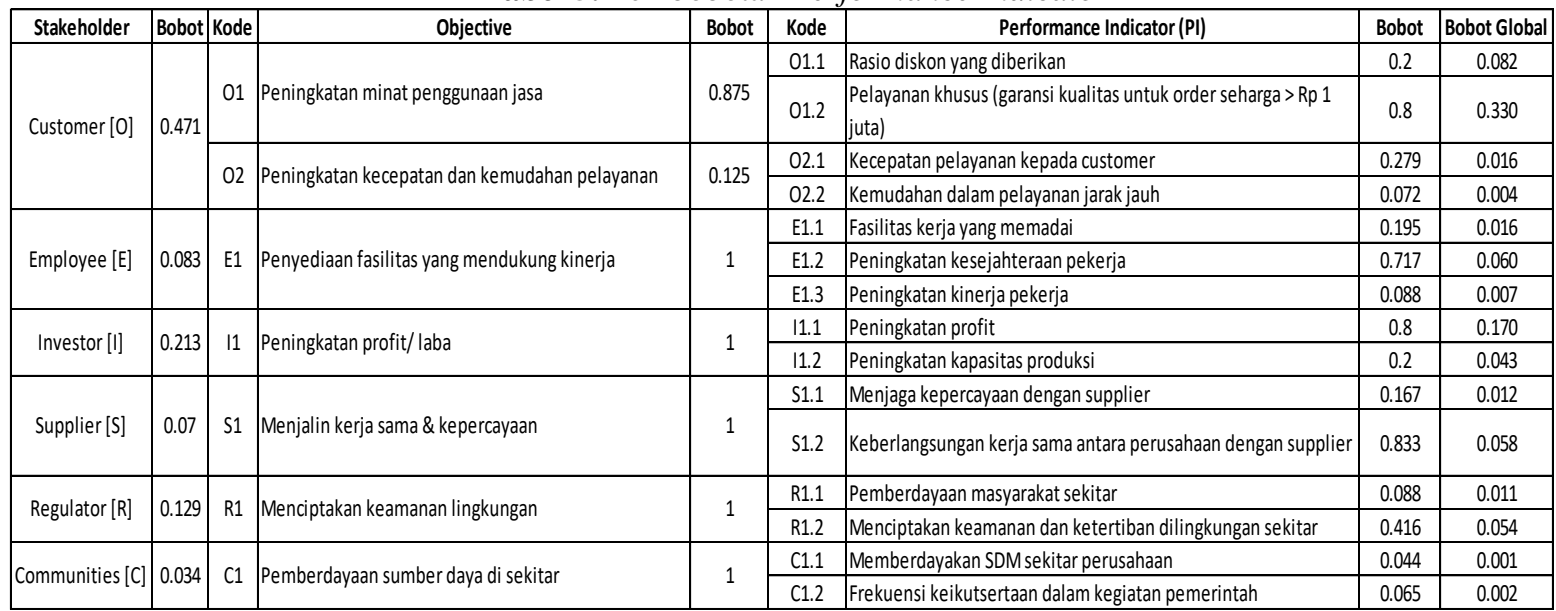


Berdasarkan hasil pembobotan global, didapatkan masalah terbesar yang paling mempengaruhi performansi perusahaan. Stakeholder customer pada tujuan utama peningkatan minat pengguna jasa, dengan PI pelayanan khusus memiliki bobot global tertinggi yaitu sebesar 0,330 sehingga pelayanan khusus kepada konsumen perlu diperhatikan oleh perusahaan. Pelayanan khusus yang diinginkan ialah bahwa CV. Cendana Offset mampu memberikan garansi kualitas untuk pesanan seharga lebih dari satu juta rupiah. Hal ini dianggap penting karena pesanan dengan nilai tersebut merupakan pesanan yang memberikan keuntungan tinggi untuk perusahaan. Maka dari itu diperlukan sebuah jaminan untuk pemesan sehingga menumbuhkan kepercayaan yang lebih erat kepada perusahaan.

Dalam industri jasa seperti jasa pencetakan, konsumen memerlukan perusahaan yang bisa melayani permintaannya secara cepat dan akurat sehingga untuk menjaga performasi dari CV. Cendana Offset perlu melakukan pengembangan-pengembangan pada pelayanan khusus kepada pelanggan yang tidak dimiliki oleh perusahaan lain. Misalnya dapat melakukan pencetakan dalam waktu kurang dari 1x24 jam atau bahkan bisa ditunggu di tempat, dapat melakukan pencetakan yang dapat disesuaikan dengan kehendak dan keinginan konsumen, memberikan diskon besar-besaran di suatu periode.

Selain membuat tawaran diskon dan layanan istimewa kepada pelanggan, kualitas produksi Cendana Offset juga perlu di tingkatkan. Untuk memenuhi permintaan pelanggan yang beragam, maka Cendana Offset perlu meningkatkan kualitas sumber daya yang ada. Misalnya kualitas operator atau desainer Cendana Offset perlu ditingkatkan dengan merekrut desainer yang sudah berpengalaman sehingga dapat mengintepretasikan keinginan pelanggan dengan baik. Selain itu kualitas mesin produksi perlu ditingkatkan dan perlu melakukan upgrade mesin, hal ini dilakukan agar tingkat produksi dan kualitas produk yang dihasilkan perusahaan bisa meningkat.

\section{Kesimpulan}

Berdasarkan pengidentifikasian kebutuhan dan kontribusi dari masing-masing stakeholder kemudian didapatkan 10 elemen KPI berdasarkan stakeholder.

Berdasarkan pembobotan global dari performance indicator diperoleh 10 elemen KPI dengan bobot terbesar pada KPI pada pelanggan atau customer. Bobot terbesar tersebut menunjukkan kebutuhan perbaikan yang harus segera dilakukan. KPI tersebut mengenai pelayanan khusus yang ditujukan untuk pelanggan. Beberapa usulan yang diperlukan untuk mengatasi masalah pelayanan khusus di CV. Cendana Offset dengan dapat dilakukan pencetakan kurang dari 1x24 jam, memberikan tawaran diskon yang lebih beragam pada periode-periode tertentu. Selain itu dapat juga dilakukan dengan peningkatan kualitas produksi melalui peningkatan kualitas sumberdaya yang ada seperti merekrut desainer yang sudah berpengalaman sehingga dapat mengintepretasikan keinginan pelanggan dengan baik dan dengan meng-upgrade mesin agar tercapai kualitas pencetakan yang lebih baik dari sebelumnya.

Model ini memiliki kelemahan dalam hal subyektivitas pengukuran dan pembobotan, namun perlu digarisbawahi bahwa karakteristik dari stakeholder itu sendiri sangatlah bias untuk diukur, sehingga mekanisme pengukuran di dalam perusahaan mempunyai warna yang berbeda dan hal ini menjadi susah dalam benchmarking. Kesulitan yang dialami dalam penelitian ini adalah dalam menemukan indikator kinerja yang tepat dan data yang akurat terutama yang terkait dengan external stakeholder, seperti pemerintah dan masyarakat sekitar. Sebagai penelitian yang berkelanjutan, diharapkan unsur subyektivitas dalam pengukuran dan pembobotan dapat lebih diminimalisir serta mencakup ke seluruh stakeholder.

\section{Daftar Pustaka}

Adianto, Saryatmo, M.A., dan Gunawan, A.S. (2014). Analisa Pengukuran Kinerja Dengan Menggunakan Metode Performance Prism dan Scoring Objective Matrix (OMAX) Pada PT.BPAS. Sinergi, Vol.18, No. 2, pp.61-70.

Arianto, E.Z., dan Partiwi, S.G. (2009). Analisa Pengukuran Kinerja Dengan Menggunakan Metode Performance Prism (Studi Kasus Pada PT. Petrokimia Gresik). Jurnal Teknik Industri Institut Teknologi Sepuluh November Surabaya. 
Ismail, T.H. (2007). Performance Evaluation Measures in The Private Sector: Egyptian Practice. Managerial Auditting Journal, Vol. 22, No. 5, pp. 503-524.

Mardiono, L., Wibisono, E., dan Jolanda, C. (2011). Pengukuran Kinerja Menggunakan Model Performance Prism. Proceedings 8th National Industrial Engineering Conference, pp. 108-115.

Puspitasari, N.B., Prastawa, H., dan Diana, A. (2012). Perancangan Sistem Pengukuran Kinerja dengan Metode Performance Prism (Studi Kasus Pada PDAM TIRTA MOEDAL Cabang Semarang Jawa Tengah). JATI Undip, Vol. 7, pp. 13-18.

Salim, I. (2013). Mengenal Dunia Industri Grafika (Cetak) Pengertian Industri Grafika, http://slideplayer.info/slide/3673350/. Diakses pada 30 November 2015.

Suliantoro, H., Intan, M.G. (2007). Perancangan Sistem Pengukuran Kinerja Dengan Metode Performance Prism (Studi Kasus di Plaza Hotel semarang). JATI Undip, Vol. 2, No. 2, pp. 49-64.

Vanany, I., dan Tanukhidah, D. (2004). Perancangan dan Implementasi Sistem Pengukuran Kinerja dengan Metode Performance Prism. Jurnal Teknik Industri, Vol. 6, pp. 148-155.

Widyawati, S., Soeparman, S., dan Soenoko, R. (2013). Pengukuran Kinerja Pada Perusahaan Furniture dengan Menggunakan Metode Performance Prism dan Analytical Hierarchy Process. Jemis Vol. 1, No. 1 , pp. $35-38$. 